\title{
Electrostatic fluidized bed deposition of a high performance polymeric powder on metallic substrates
}

\author{
M. Barletta*, V. Tagliaferri \\ Department of Mechanical Engineering, University of Rome "Tor Vergata", Via del Politecnico, 100133 Rome, Italy
}

Received 24 November 2004; accepted in revised form 2 February 2005

Available online 31 March 2005

\begin{abstract}
The electrostatic fluidized bed deposition of a single-layer PPA 571 coating onto low carbon steel rods is reported.

A full factorial experimental design was developed in order to study the influence of several operative variables on the effectiveness of the coating process and on the coating thickness and uniformity. The operative variables included exposure time, air flow, the applied voltage, attitude, and the radial and vertical location of the work-piece in the fluid bed. After the experimentation, several process maps were developed as a support to identify the best way to lead the coating process. Finally, by using a statistical approach, the reliability and repeatability of the coating process was also established.

Experimental trends were consistent with theoretical expectation. A significant growth in achievable coating thickness was obtained by increasing voltage and air flow. Furthermore, at higher values of exposure time and applied voltage, relevant back ionization phenomena occurred, which simultaneously caused a top limit in coating thickness and a worsening of surface finishing.

Process characteristics, leading mechanisms, and some practical aspects are also discussed in detail.

(C) 2005 Elsevier B.V. All rights reserved.
\end{abstract}

Keywords: Electrostatic fluidized bed; Coating process; Corona charging; Polymer powder

\section{Introduction}

For most coating requirements, powders are electrostatically charged and delivered to metal and non-metal (including glass, ceramics, plastics and wood) substrates, which have either been pre-formed or post-formed. Many items extensively used in most decorative and functional segments of industrial markets are generally powder coated: appliances (coolers, freezers, washers, microwaves, conditions), architectural features (extrusions for windows and door frames, panelling), lawns and gardens (outdoor furniture, garden tools, and tractors), leisure time (bicycle and vehicles frames, hand tools), anti-corrosion (drill pipes, rebars, valves and fixtures, motor blocks), automotive (truck primers/surfacers, wheels, bumpers, mirrors), office furniture (desks, filing cabinets, book cases, computer related

\footnotetext{
* Corresponding author.

E-mail address: barletta@mail.mec.uniroma2.it (M. Barletta).
}

equipment), electrical (cabinets, components cable trays, lamp housing).

Application methods include electrostatic spray guns, electrostatic brushing, powder cloud, and fluidized bed dipping. Compared with the other deposition techniques, in most cases the electrostatic spray process is more flexible and versatile. Nevertheless, when very thick and uniform coatings have to be applied $(>250 \mathrm{~mm})$ in one application and curing cycle, the electrostatic fluidized bed [1] process is a very promising and competitive deposition technique because its initial plant cost and maintenance costs are low. In fluidized bed powder coating, work-pieces are either dipped directly into a reservoir of fluidized powder or passed through an electrically charged cloud of powder, which is created above a container of fluidized powder. Although it seems to be a relatively simple process, questions abound regarding the applications, benefits and costs of fluidized bed powder coating.

Most of papers in the literature concern conventional fluidized bed coating [2-5]. Several papers in the 
seventies concentrate on fluidized bed operative variables [2-4] and on the other phases of the deposition process [3-5]. Further relevant developments are revealed in the literature during the nineties. Attention was focused on the employment of new raw materials [6,7], on new systems to monitor and control the process [8], and on simulation techniques $[9,10]$ which, making use of commercial or self-programmed software, attempted to reproduce the fluidized bed deposition process. Since then, there have been further attempts to specialize the conventional fluidized bed deposition process by using high performance polymer alloy [11], manufactured ad hoc, and to employ new advanced simulation software in order to foresee the best deposition operative parameters in several working conditions and on work-pieces with differing and complex shapes [12].

Scientific literature concerning electrostatic fluidized bed deposition is still lacking. There are a few studies but these only relate to industrial applications such as Tshaped components or tubular intersections [13] and rotors [14]. Otherwise their analysis is too specialized, such as the computing of electric fields in a fluidized bed of electrostatically charged or tribocharged powders by using finite element methods [15]. As yet, there has been no interrelated analysis of powder properties and fluidized bed process parameters which include exposure time, air flow, applied voltage, specimen location and attitude in the bed, as well as powder size and distribution. Consequently, this paper develops a full factorial experimental plan in order to analyze the influence of several operative variables, the raw materials employed, and the set-up of the deposition system on the coating performance. This was expressed in terms of achievable coating thickness and in terms of coating thickness uniformity. A statistical approach was also taken in order to estimate the reliability and repeatability of the experimental results in determining the coating thickness in several different process conditions.

Lastly, experimental data may be used in the future as the basis for modeling the experimental results, and to develop an analytical instrument. This will be able to predict the coating thickness trend by simply setting the operative variables and the calibration coefficients, and provides cues on the best way to deal with them.

\section{Experimental apparatus and procedure}

\subsection{Fluidized bed coating and apparatus}

The fluid bed was constructed as a tank $(250 \mathrm{~mm}$ in diameter and $600 \mathrm{~mm}$ in height), the bottom part of which is an air plenum chamber and the top part is a porous plate, which is used to sustain powder and at the same time allows the fluidization air to pass through (Fig. 1). This system incorporates a set of electrodes in the powder chamber, even though alternative solutions are possible. The corona charging method, which makes use of a high voltage generator $(0-100 \mathrm{kV})$, was employed in order to bring an electrostatic charge (mostly negative) onto the powder particles through the intermediate process of creating oxygen ions.

The upper part of the tank (above the plate) is halffilled with a certain volume of powder $(300 \mathrm{~mm}$ in height), which is fluidized by ionized air from below. With the help of the transport air, the resulting electrically charged cloud of powder moves in the direction of the grounded work-piece (target). As the charged particles

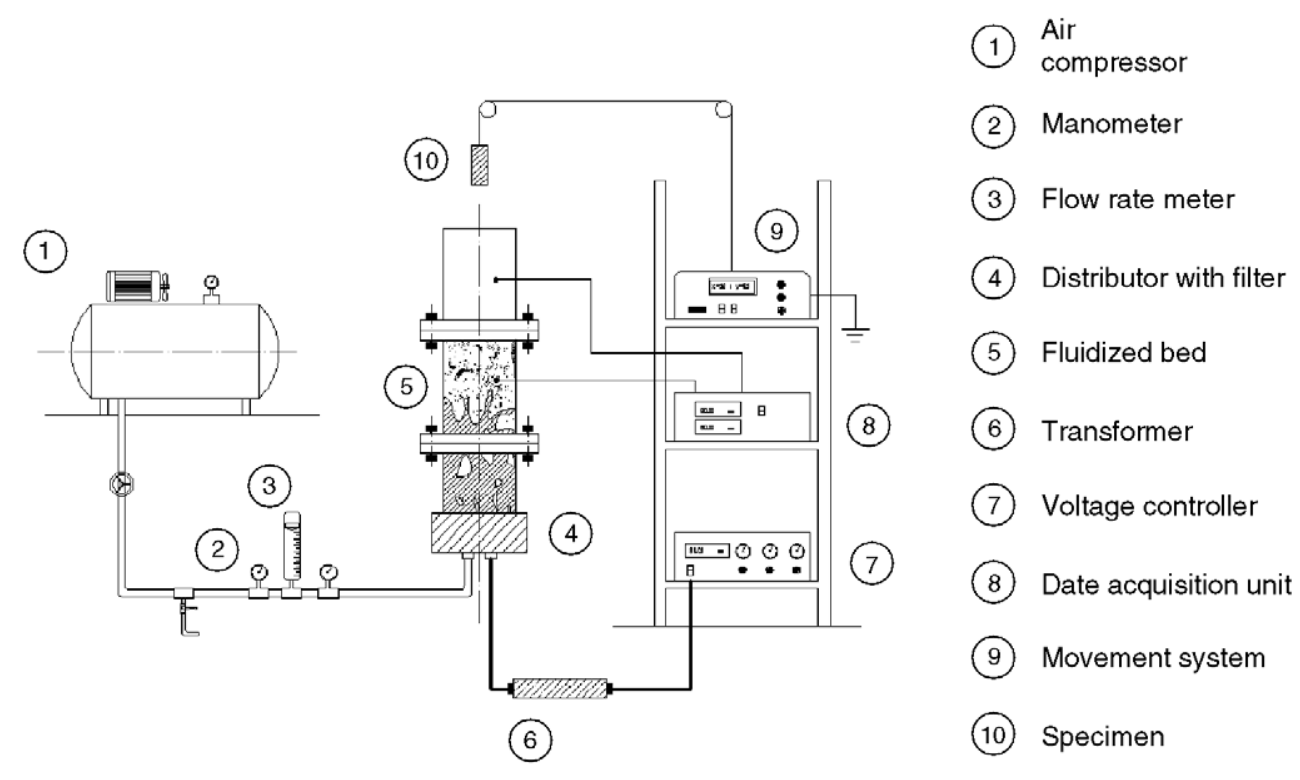

Fig. 1. Schematic view of experimental apparatus. 
come close to the target, electrostatic force causes the particles to be deposited on and adhere to the target when it is passed into or through the powder cloud or just hung in the cloud. With this system target preheating is not necessary. Small amounts of powder on the fluidization plate are necessary and the suspension of less dense powder means film thickness can be accurately controlled. This system also eliminates the need for dipping because powder rises to the work-piece. Since the work-piece is not preheated before being coated, powder can be readily removed from areas that are to be left bare, eliminating the need for mechanical masking and all the problems associated with it.

\subsection{Materials and preparation of specimens}

Electrostatic fluidized bed coating experimental tests were performed upon low carbon steel (AISI1040) rods, typically used as raw materials for fence posts, fencing panels, sign posts, street furniture, balustrading, stadium seating, pipes including drinking water, cable tray and ducting, garden furniture, gutter brackets, battery boxes, and wirework. That is to say, a material widely used in many industrial segments.

Six meter long steel rods (with a square cross-section of $10 \mathrm{~mm}$ each side) were cut into pieces $60 \mathrm{~mm}$ in length. The work-pieces were then subjected to a set of surface pretreatments in order to improve the adhesion of the coating on them. A vapour degreasing cleaning employing common solvents to remove oil, grease, loose metal chips, and other contaminants from the surface, which was followed by a zinc phosphating, in which both the coating weight and the crystal size were accurately controlled. An additional acid cleaning step was necessary when rust and scale needed removing. At the end, a rinsing cycle was applied to flush away the remaining 'drag-out' from the previous bath and to neutralize the surface.

Once all the impurities on the metal surface had been removed, the surface was conditioned so that the adhesion of the coating film would be optimal. Because it provides a uniform surface on the substrate resulting in the absence of flash rust, powdering and windowing, an iron phosphate was applied to provide the best basis for bonding the powder coating film to the metal surface.

The coating material used was Plascoat PPA $571 \mathrm{H}$ manufactured by Plascoat Systems Limited. It is a thermoplastic polyolefin based alloy, designed for use in fluidized bed dipping. When correctly applied over a suitably prepared metal surface, Plascoat PPA $571 \mathrm{H}$ provides an excellent long-term corrosion resistant coating. The coating maintains excellent adhesion by chemically bonding to the metal substrate without the need for a separate adhesive primer. Table 1 summarizes the typical properties of the material.
Table 1

Typical property of PPA $571 \mathrm{H}$

\begin{tabular}{lll}
\hline Property & Regulation & Value \\
\hline Specific gravity & & $0.96 \mathrm{~g} / \mathrm{cm}^{3}$ \\
Tensile strength & ISO 527 & $17 \mathrm{MPa}$ \\
Elongation at break & ISO 527 & $500 \%$ \\
Brittleness temperature & ASTM D-746 & $-76{ }^{\circ} \mathrm{C}$ \\
Hardness & Shore A & 95 \\
& Shore D & 52 \\
Vicat softening point & ISO 306 & $80{ }^{\circ} \mathrm{C}$ \\
Melting point & & $105{ }^{\circ} \mathrm{C}$ \\
Tear strength & ASTM D1938 & $22 \mathrm{~N} \mathrm{~mm}$ \\
Stress cracking & ASTM D1693 & Greater than $1000 \mathrm{~h}$ \\
Toxicity index & NES 7 & 1.8 \\
Flammability & UL94 3.2mm & Unrated \\
& moulding & \\
Dielectric strength & IEC 243 VDE 0303 & $39 \mathrm{KV} / \mathrm{mm}$ at $500 \mu$ \\
Volume resistivity & ASTM D-257 & $3 \times 10^{17} \mathrm{Ohm}-\mathrm{cm}$ \\
Surface resistivity & IEC 93 & $8 \times 10^{17} \mathrm{Ohm}$ at $350 \mu$ \\
\hline
\end{tabular}

\subsection{Test parameters and coating procedures}

The experimental tests thoroughly investigated the exposure time, the air flow fed to the fluid bed, the voltage applied to the electrodes in the air plenum chamber, the attitude of the target in the fluid bed, the radial and vertical location of the target in the fluid bed. Table 2 summarizes the experimental design.

A full factorial campaign repeated five times was used in order to analyze the influence of exposure time, air flow and applied voltage on coating thickness. A standard condition $\left(6 \mathrm{~s}\right.$ exposure time, $9 \mathrm{~m}^{3} / \mathrm{h}$ air flow, and 65 $\mathrm{kV}$ applied voltage) was used to check the other three variables investigated, that is, the attitude of the target (the angle between the vertical axis of the fluidized bed and the vertical axis of the target) and its radial and vertical position (expressed in terms of dip distance, that is, the distance of the target from the top of the fluidized bed) in the bed. More than 400 tests were performed. The scheduled protocol during the execution of experimental tests was composed of:

- The specimen surface was accurately cleaned and prepared for the deposition process.

- Once the specimen surface had been pre-treated, the electrostatic fluid bed system was switched on. A cloud of charged particles rapidly rose from the bottom of the fluidization chamber.

- The specimen was then hung in a 'built ad hoc' holder and then dipped in the electrostatically charged cloud of particles in the fluid bed. The longest side of the specimen $(60 \mathrm{~mm})$ was located along the $\mathrm{z}$-axis of the column to check the coating vertical uniformity. The target position in the bed was varied by activating a CNC system which allowed the movement along the three axes to be controlled. The position of the specimen was kept constant throughout each experimental test. 
Table 2

Full factorial experimental plan

\begin{tabular}{|c|c|c|c|c|c|c|}
\hline \multirow[t]{2}{*}{ Levels } & \multicolumn{6}{|l|}{ Factors } \\
\hline & $\begin{array}{l}\text { Exposure } \\
\text { time (s) }\end{array}$ & $\begin{array}{l}\text { Air flow } \\
\left(\mathrm{m}^{3} / \mathrm{h}\right)\end{array}$ & $\begin{array}{l}\text { Applied } \\
\text { voltage } \\
(\mathrm{kV})\end{array}$ & $\begin{array}{l}\text { Attitude } \\
\left({ }^{\circ}\right)\end{array}$ & $\begin{array}{l}\text { Radial } \\
\text { position } \\
(\mathrm{mm})\end{array}$ & $\begin{array}{l}\text { Vertical } \\
\text { position } \\
(\mathrm{mm})\end{array}$ \\
\hline I & 3 & 6 & 50 & 0 & North & 24 \\
\hline II & 5 & 8 & 60 & 30 & South & 26 \\
\hline III & 8 & 10 & 70 & 60 & East & 29 \\
\hline IV & 10 & 12 & 80 & 90 & West & 33.5 \\
\hline V & & & 90 & & & 38.5 \\
\hline
\end{tabular}

- Once coated, the specimen was removed from the fluid bed and picked up from the holder with the utmost care. A heating cycle was applied to melt the coating and to obtain the best finish for the specimen surface after the coating process.

- After being heated in an electrical oven, each specimen was left to cool slowly in the oven without being moved. The amount of coating still clinging to the surface was then accurately measured by using the MEGACHECK $5 \mathrm{~F}-\mathrm{ST}$ instrument.

The means of the experimental data were then calculated and reported. Measures of variability were reported in terms of standard deviation. Lastly, experimental data collected was checked by employing a general linear model ANOVA on each family of process conditions. Furthermore, a set of process maps was built in which the coating thickness was reported in great detail by varying the exposure time, the air flow, and the applied voltage.

\section{Experimental results and discussion}

\subsection{PPA 571 hydrodynamic behavior and thermal analysis}

A previous paper [16] investigated the hydrodynamic behavior of Plascoat PPA 571 powder in great detail. The distribution peak of the unsieved Plascoat PPA 571 powder lay in the range $100-150 \mathrm{~mm}$, and its cumulative curve showed $95 \%$ of the grain size distribution to be below 250 $\mathrm{mm}$. A minimum fluidization velocity of $0.0032 \mathrm{~m} / \mathrm{s}$ was measured. Bubbling regime was kept in an air flow range of $3.5 \mathrm{~m}^{3} / \mathrm{h}$ to $7 \mathrm{~m}^{3} / \mathrm{h}$, which meant superficial velocities varying in a range of 5-10 times the minimum fluidization velocity. Employing an air flow in the range between 8-12 $\mathrm{m}^{3} / \mathrm{h}$ meant significant elutriation phenomena occurred.

Fig. 2 describes the distribution of coarse $(\mathrm{TDH}(\mathrm{C}))$ and fine $(\mathrm{TDH}(\mathrm{F}))$ powders in the free board zone of the bed. Parts being coated were located above the dense phase at different vertical locations in the free board and consequently exposed to particles with different sizes. However, the higher the location of the part in the bed, the smaller the grit size distribution in the vicinity of the part itself and the fainter the erosion phenomena caused by the spout from the dense phase. At the same time, going further away from the bed wall, the bed density increased and there was no risk of wall layer agglomerates falling on the exposed part.

\subsection{Analysis of exposure time, voltage and air flow}

The influence of all the investigated variables on coating thickness trend and uniformity was analyzed. Firstly, the influence of exposure time, applied voltage and superficial

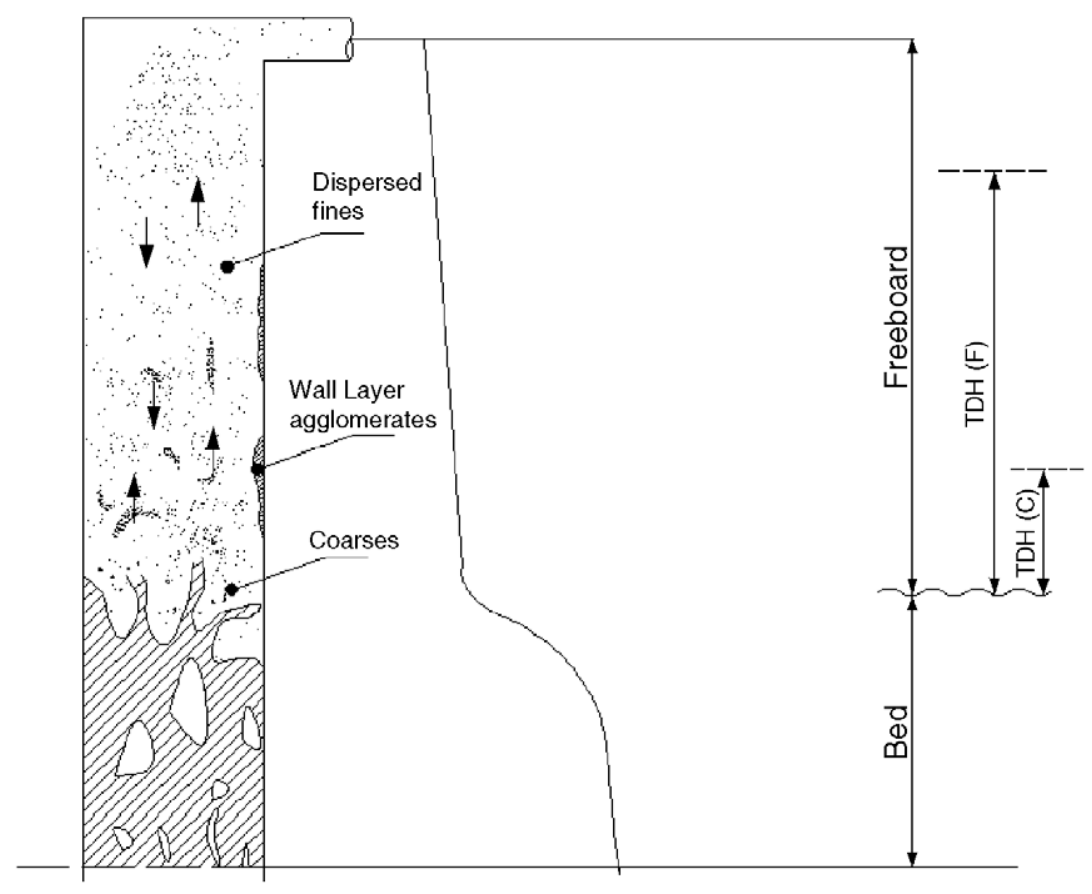

Fig. 2. Schematic view of fluidized bed hydrodynamic during coating process. 
velocity, that is, air flow, on coating thickness trend was examined.

Experimental data collected are summarized in Fig. 3 which reports the results of the analysis of means (ANOM). Results consistent with theoretical expectations were found. The trends found show that increasing each of the three investigated process parameters resulted in a significant growth in coating thickness.

Subsequently, three related process maps based of all the experimental data were built. Trends in process maps can be explained as a result of forces involved in the deposition process. As is known, there are four forces acting on a charged particle as it travels from the fluidized bed dense phase to the grounded work-piece, namely: the aerodynamic force, the electrical force, the weight, and the air resistance. It should be noted that the 'attractive' forces, pushing the particle towards the target, are the electric force, which determines the attraction between powder and grounded substrate and the consequent adhesion thanks to the rapid polarization of the metal substrate ('mirror charge'), and the air stream, which effectively delivers the particle to the part. However, if the particle is not sufficiently charged or the field strength is not sufficient either, the particle will bounce off the metal substrate and be either carried away by the air stream or dropped down under the force of gravity before the force of attraction between the charged particle and the grounded substrate takes effect.

In agreement with the above considerations, an increase in the applied voltage caused a subsequent growth in coating thickness, resulting in the electrical force enhancing its positive effect on the coating thickness (Fig. 4). On the other hand, an increase in air flow, producing a significant increase in elutriation phenomena, caused more powder to be available in the vicinity of the target and so greater coating thickness could be expected. At the same time, increases in air flow over $9-10 \mathrm{~m}^{3} / \mathrm{h}$ caused massive erosion of powder which had just adhered on the target but had not yet consolidated, resulting in no relevant changes in coating thickness occurring (Fig. 4). Moreover, a reduction in

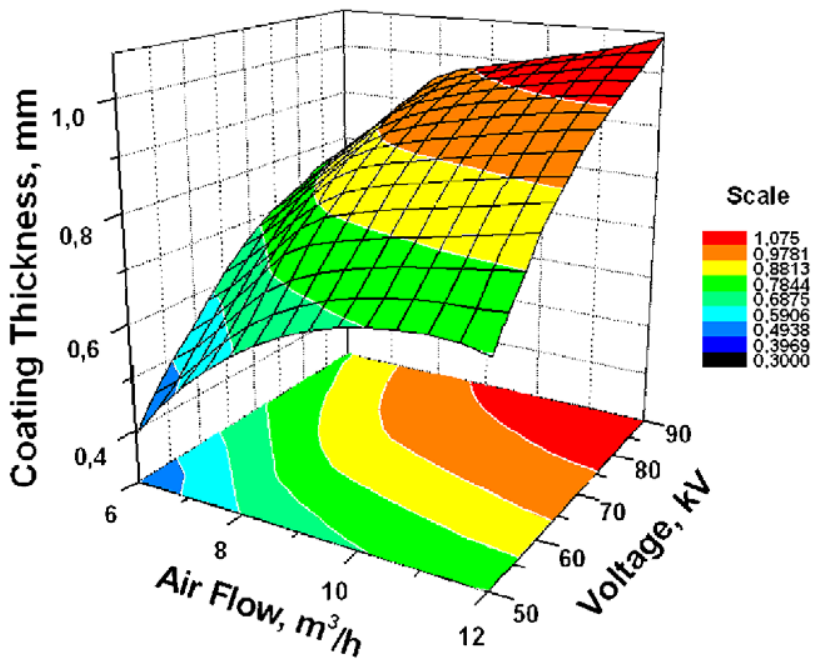

Fig. 4. Coating thickness produced by varying air flow and voltage (exposure time set at $5 \mathrm{~s}$ ).

coating thickness occurred for low voltage where electric attraction force was fainter $(50 \mathrm{kV})$.

Fig. 5 shows that an increase in the exposure time and air flow determined thicker coatings due to large amount of powder being delivered close to the target. It was noted that in map portion characterized by higher air flow level, values over $9-10 \mathrm{~m}^{3} / \mathrm{h}$ were not associated with further growth in coating thickness. This was the result of massive stripping from the external layer of weakly adhered powders produced by air stream.

Quite a different situation arises when the interrelated effect of the applied voltage and the exposure time are analyzed (Fig. 6). For lower values of both these parameters (up to $8 \mathrm{~s}$ exposure time and $70 \mathrm{kV}$ applied voltage), an increase produced significant increases in the deposited film in agreement with the previous theoretical observations. Nevertheless, further increase in both of these parameters gave rise to an inversion phenomenon with a consequent reduction in film deposited on the metal substrate.

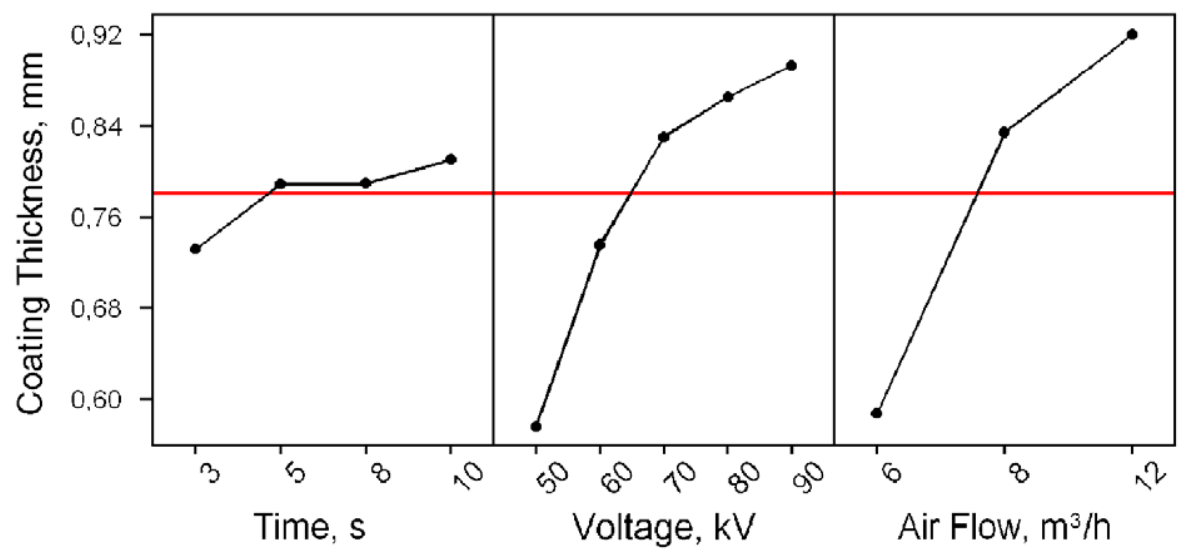

Fig. 3. ANOVA: main effects plots for means. 


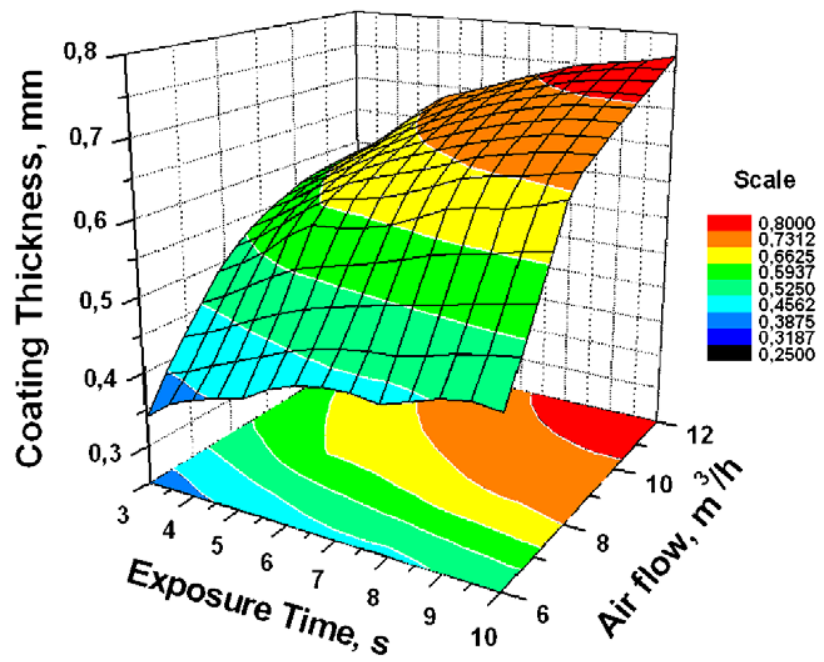

Fig. 5. Coating thickness produced by varying exposure time and air flow (voltage set at $50 \mathrm{kV}$ ).

It stands to reason that continuing to deliver charged powders on the same surface ultimately leads to back ionization occurring. In fact, when electrostatically charged powders are applied to the metal surface, the strength of the electric field inside the coating layer progressively comes up with its thickness concurrently causing a related growth of mirror charge inside the metal. Lastly, in continuing to apply charged powder for long periods of time at high voltages, the strength of the electric field inside the coating layer becomes self-sufficient in ionizing air trapped between powder particles. The ionization process inside the coating layer causes stray electrons present in the air to start moving faster in the electric field, with split air molecules giving rise to a large number of negative electrons and positive ions. Because opposite charges attract, negative electrons rush toward the grounded substrate which is relatively positive because of the presence of the mirror charge. On the contrary, positive ions try to escape from the coating layer

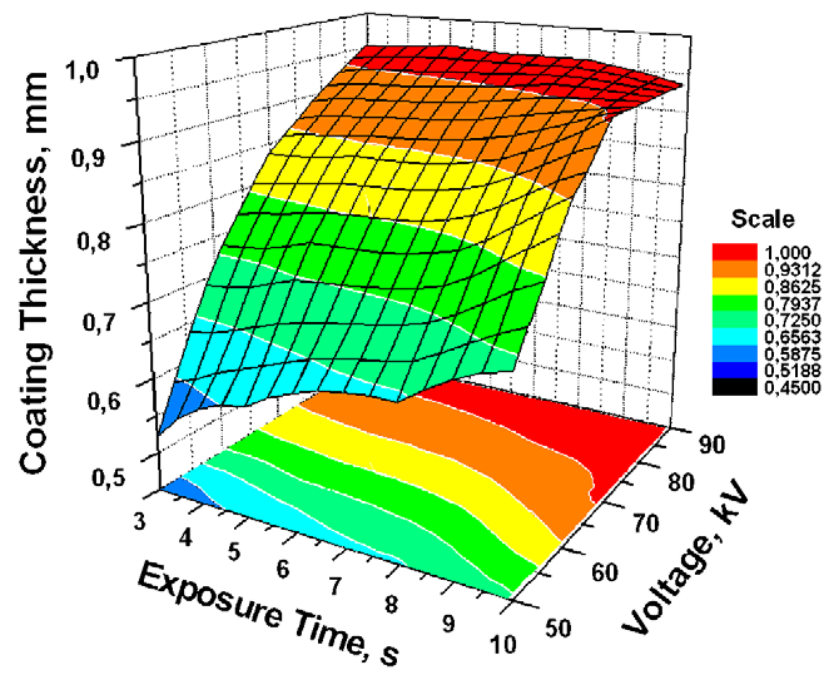

Fig. 6. Coating thickness by varying exposure time and voltage (air flow set at $8 \mathrm{~m}^{3} / \mathrm{h}$ ). toward the negative electrode. As a consequence of this massive flow of electrons and ions travelling in opposite directions, miniature lightning or spark shootings (streamers) develop through the layer of powder coating. This phenomenon, the back ionization, is the driving force behind what is often called the self-limiting property of the powder coating process because it greatly reduces transfer efficiency, as shown in Fig. 7. In accordance with theoretical expectations, this phenomenon was accompanied by a significant deterioration of surface finishing in the form of micro-craterization of the coating, as well as voids, pin holes, and the 'orange peel' effect.

Closer examination of Fig. 7 shows that at $90 \mathrm{kV}$, the rapid development of a thick coating can already be seen at low exposure time. As a result of back ionization phenomena, increasing exposure time means only thinner coating with worse surface finishing can be obtained. So, a voltage threshold level set at $70-80 \mathrm{kV}$ avoids any back ionization being initialized.

Lastly, the relative influence of the three parameters is discussed in detail by using a statistical approach. The results of a general linear model ANOVA are reported in Table 3. The Fisher factors in Table 3 show that two of the three parameters experienced a significant influence on achievable coating thickness with high percentage contribution values. The most important factors were the applied voltage and the air flow. In addition, a contribution percentage of just $4.4 \%$ was estimated for the factor 'error', conferring further reliability on the experimental results.

No analogous results on the influence of process parameters on electrostatic fluidized bed deposition are reported in the literature, so no direct comparison is possible. However, similar analysis can be found for electrostatic spraying in which parameters such as voltage, current, spray time, powder feeding rate, atomization and so on have been thoroughly investigated [17-19]. Direct comparison is not possible, and yet both the application techniques show very similar trends in coating thickness with spray time (exposure time), voltage and powder feeding rate (air flow) [17,18].

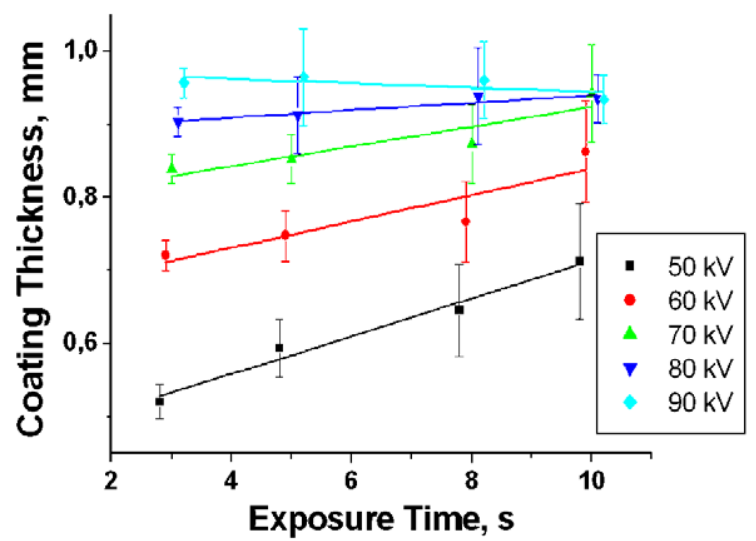

Fig. 7. Coating thickness produced by varying exposure time and the applied voltage parameter (air flow set at $8 \mathrm{~m}^{3} / \mathrm{h}$ ). 
Table 3

ANOVA on the three leading factors

\begin{tabular}{lcllcr}
\hline Factors & \multicolumn{2}{l}{ Indices } & & \\
\cline { 2 - 6 } & DoF & SSk & MSk & \multicolumn{1}{c}{ Fk } & Pk (\%) \\
\hline Exposure time $(\mathrm{s})$ & 3 & 0.051 & 0.017 & 8.98 & 2.5 \\
Applied voltage $(\mathrm{kV})$ & 4 & 0.796 & 0.199 & 104.1 & 37.2 \\
Air flow $\left(\mathrm{m}^{3} / \mathrm{h}\right)$ & 2 & 1.196 & 0.598 & 312.7 & 55.9 \\
Error & 50 & 0.095 & 0.001 & & 4.4 \\
Total & 59 & 2.140 & & & \\
\hline
\end{tabular}

\subsection{Analysis of specimen location and fluidized bed} hydrodynamic on coatings

The analysis of specimen location and influence of fluidized bed hydrodynamic on coating process effectiveness was thoroughly investigated. Some useful experimental results are reported in Figs. 8 and 9.

The attitude of the specimen did not appear to influence the coating thickness. Fig. 8 shows that, working in standard condition, a coating thickness of about $0.60 \mathrm{~mm}$ could be achieved for each attitude investigated. This result is in contrast with trends achieved for conventional fluidized bed coating process in which specimen location in the range 60 $90^{\circ}$ had to be avoided [16]. In fact, in that case, in varying part attitudes from $0^{\circ}$ to $90^{\circ}$, the literature reported thicker coatings due to the stagnation of powder on the top of the part, which determined a sort of 'bowl' effect on the less fluidized powders above it [16]. In addition, the results in the literature indicated that bottom sides of parts became increasingly rich in deposited powder going towards attitude of $90^{\circ}$ because of the screen effect of the part which, reducing the fluidization below itself, caused a preferential drop of powder [16].

In our process, neither of these negative effects significantly influenced the coating thickness. The reason probably lies in the difference in coating process between the conventional fluidized bed and the electrostatic fluidized bed. In the first, the work-piece is totally dipped in the dense phase, definitely modifying the hydrodynamic of the bed. In

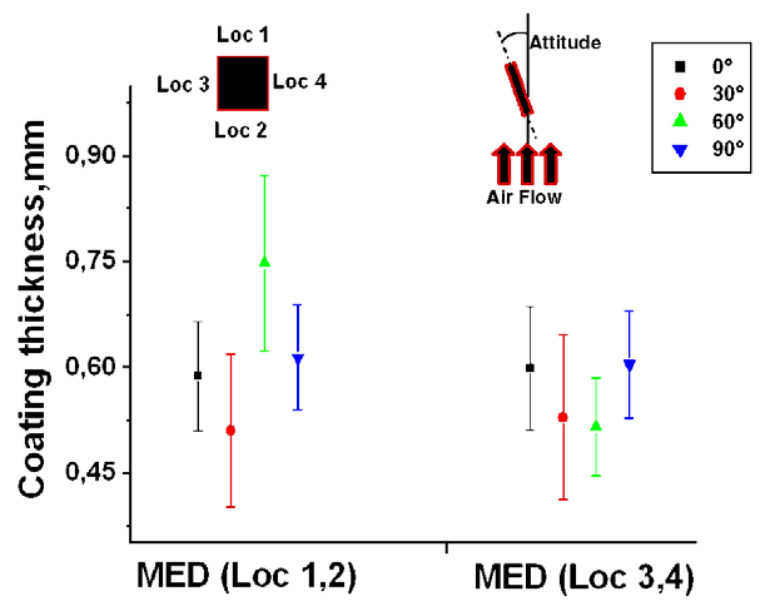

Fig. 8. Coating thickness produced by varying specimen attitude.

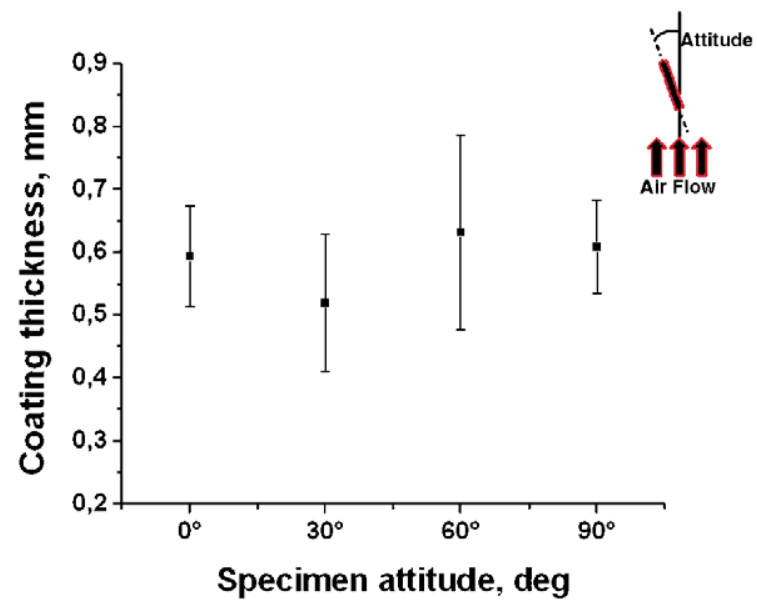

Fig. 9. Coating thickness produced by varying specimen attitude averaged on all the sides.

contrast, in the electrostatic fluidized bed the work-piece is lowered in the bed without being dipped in the dense phase. It is located in the free board zone at a variable distance from the dense phase. Consequently, no strict influence on the hydrodynamic of the dense phase of the bed is caused by location of the work-piece, and the influence of attitude in determining the coating thickness results is found to be very slight, as shown in Fig. 9. The experimental results in Fig. 9 were averaged over 12 measurements, three for each side of tested specimen, and demonstrate the invariance of the coating thickness with the specimen attitude.

On the other hand, the freeboard hydrodynamic of the fluidized bed strongly influenced the coating thickness. As reported in Figs. 10 and 11, a physical interpretation of coating thickness trend is possible. In Fig. 10, the highest values of coating thickness are related to specimen located in the middle of the freeboard of the fluid bed. It is in this location that the amount of powder moving upward in the bed is the greatest, resulting in higher deposition speed on part surface. On all sides of the fluid bed, because of descending convective motions [1] and of wall resistance to the powder, which raises the bed upward, the deposition

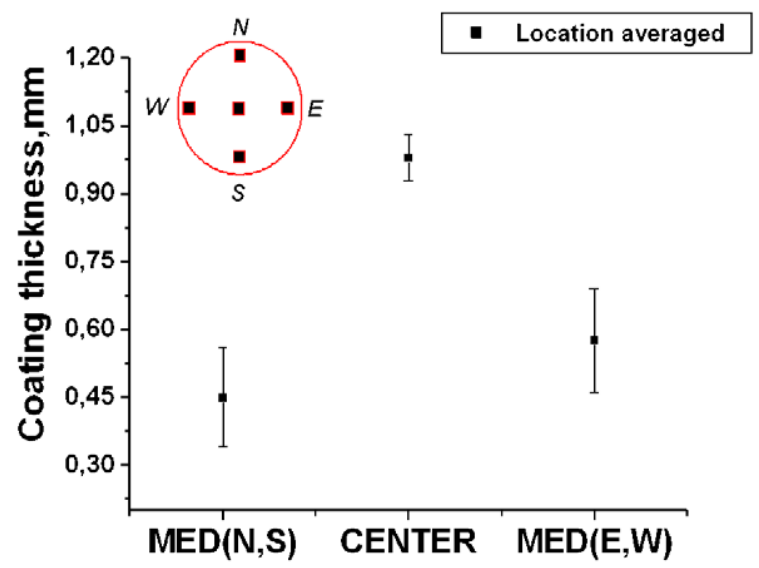

Fig. 10. Coating thickness produced by varying specimen radial location. 


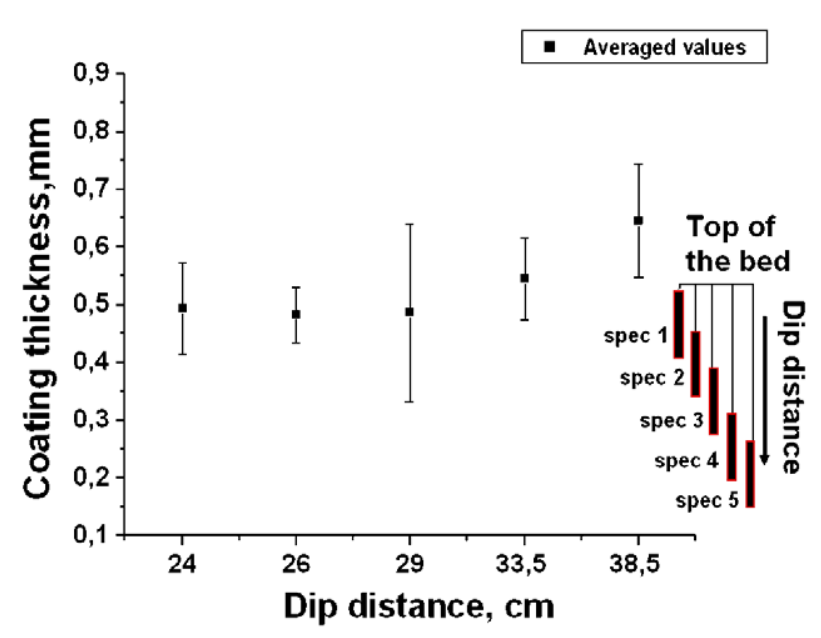

Fig. 11. Coating thickness produced by varying specimen vertical location.

speed progressively decreases, resulting in the smallest values of coating thickness.

No direct comparison is possible with analogous experiments concerning conventional fluidized bed reported in the literature. In fact, as mentioned above, in that case the workpiece is totally dipped during the dense phase in which the powder is largely available in all the radial positions resulting in no significant differences in coating thickness [16].

In the same way, a strong influence on coating thickness was determined by the vertical location. Two leading effects probably determined the typical trend reported in Fig. 11. In the zone far from the dense phase (low values of dip distance), the work-piece is dipped in a cloud composed of dispersed fines only. There is no erosion in this zone due to spout from the dense phase or caused by powder travelling at too high a speed, and an asymptotic and very stable trend in coating thickness can be detected. The increase in the coating thickness on coming closer to the porous plate distributor is related to the displacement of the work-piece in a zone closer to the dense phase characterized by a cloud richer in highly electrostatically charged coarse grains (Fig. 2 ). This trend differs strongly from that achieved in conventional fluidized bed in which the work-piece, being dipped in the dense phase, is coated again and again by coming closer to the bottom part of the bed, denser in powder [16].

\subsection{Uniformity of coatings thickness and surface monitoring of coated parts}

The uniformity of the coating thickness was checked in terms of both the dip time and of the vertical location in the bed. Good results were achieved in both of the situations investigated (Figs. 12 and 13). Regarding the dip time, a relevant unevenness was only noted at higher values (Fig. 12). Lower dip time values were associated with the highest level of coating thickness uniformity. In according with previous observations, when the part was kept fixed very far

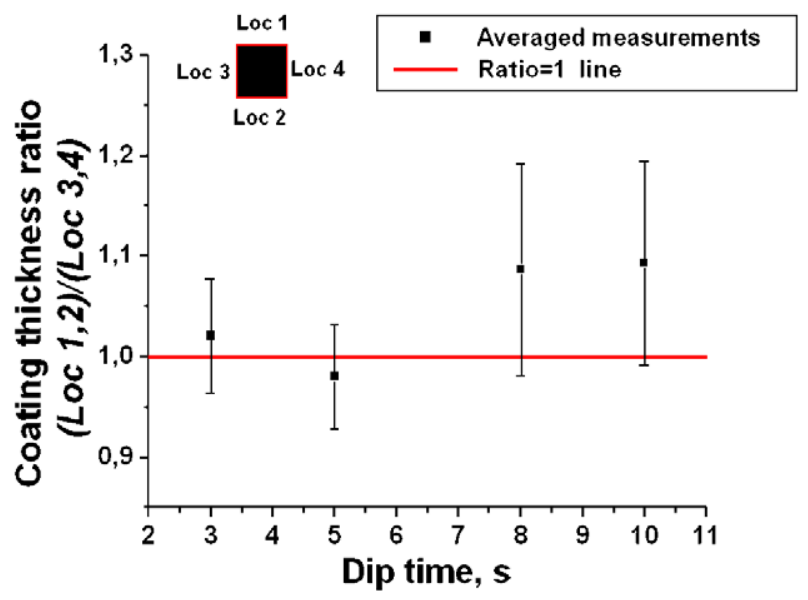

Fig. 12. Coating thickness uniformity produced by varying dipping time.

from the dense phase, paying attention to vertical location brought about good evenness of coating (Fig. 13).

Coming progressively closer to the dense phase, larger differences in coating thickness became evident and stood out. In this situation, the coating deposition was caused by a phase of electrical charged dispersed fines and coarse particles which are very susceptible to the hydrodynamic behavior of the bed (spout, instability, and so on).

Therefore, slight variations in bed hydrodynamic simultaneously determined considerable modifications in particle distribution and movement, and also in coating thickness. Once again, comparing typical uniformity values detected for conventional fluidized bed deposition [16], and for electrostatic spraying $[18,19]$, with those detected for electrostatic fluidized bed coating, emphasizes the high performance which can be reached by the latter deposition technique. The electrostatic fluidized bed coating simultaneously produces coating characterized by high thickness values and good uniformity.

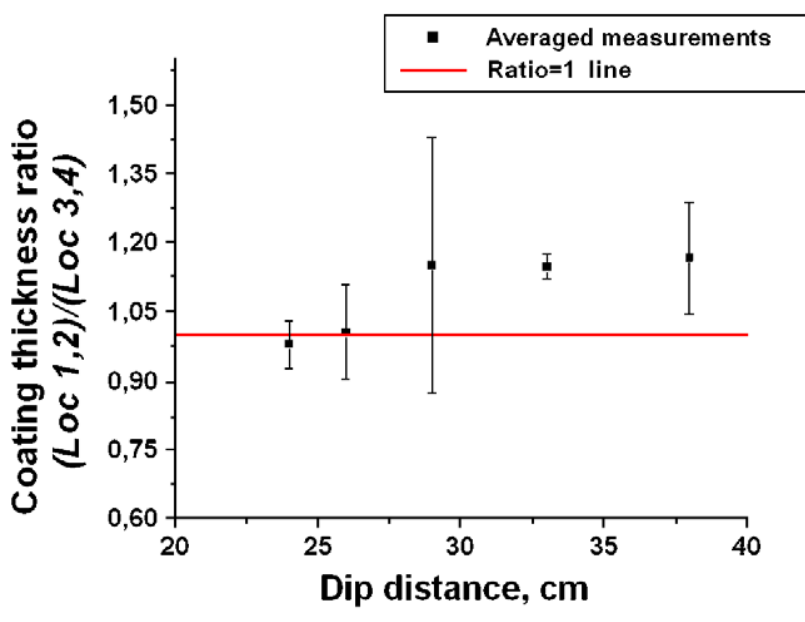

Fig. 13. Coating thickness produced by varying specimen vertical location. 


\section{Conclusions}

The analysis of the most influential process parameters was presented in this paper. Exposure time, applied voltage, and air flow were initially investigated. The analysis of mean was performed on these variables, generating a simple method to estimate the coating thickness once the level of time, air flow and voltage had been defined. From the three parameters of the exposure time, the applied voltage and the air flow, the ANOVA demonstrated that the last two parameters had a stronger influence.

Three process maps were built in which trends in coating thickness were found consistent with theoretical expectation. A significant growth in achievable coating thickness was obtained by increasing voltage and air flow. At higher values of both exposure time and applied voltage, relevant back ionization phenomena occurred, which simultaneously caused a top limit in coating thickness and a worsening of surface finishing ("orange peel" effect). In addition, the location of the part in the bed and its attitude had a considerable influence on effectiveness of coating process. Specimen attitude did not seem to influence coating distribution on the part, demonstrating that the high performance is also achievable when employing electrostatic fluidized bed deposition on parts with complex shape. In fact, whatever the impact angle between powder and part, the coating kept its uniformity around the part itself. The vertical location influenced the coating thickness by producing higher thickness when the target comes closer to the dense phase where large particles with massive electrical charge were available for deposition on the grounded substrate. Regarding the thickness uniformity, good evenness of coating was obtained by varying both the exposure time and the vertical location in the bed, conferring high flexibility to the examined process compared to conventional fluidized bed deposition, as extensively mentioned above.

\section{References}

[1] J.F. Richardson, in: J.F. Davidson, D. Harrison (Eds.), Fluidization, Academic Press, New York, 1971.

[2] D.S. Richart, Plast. Des. Technol. 2 (1962) 18.

[3] D.S. Richart, Plast. Des. Technol. 2 (1962) 26.

[4] C.K. Pettigrew, Mod. Plast. 44 (1966) 111.

[5] C.K. Pettigrew, Mod. Plast. 44 (1966) 150.

[6] K.C. Leong, G.Q. Lu, J. Mater. Process. Technol. 48 (1995) 525.

[7] K.C. Leong, G.Q. Lu, V. Rudolph, J. Mater. Process. Technol. 89-90 (1999) 354

[8] K.C. Leong, G.Q. Lu, V. Rudolph, Chem. Eng. Process. 41 (7) (2002) 567.

[9] K.C. Leong, G.Q. Lu, V. Rudolph, Chem. Eng. Sci. 54 (8) (1999) 1145 .

[10] K.C. Leong, G.Q. Lu, V. Rudolph, Chem. Eng. Sci. 56 (17) (2001) 5189.

[11] M. Barletta, F. Quadrini, V. Tagliaferri, Proceeding of International Conference the Coatings, 2002, Thessalonica, Greece.

[12] M. Barletta, S. Guarino, V. Tagliaferri, Proceeding of International Conference the Coatings, 2002, Thessalonica, Greece.

[13] F.S. Ali, I.I. Inculet, IEEE Trans. Ind. Appl. 36 (5) (2000) 1247.

[14] M.R. Strucaly, Electrostatic powder coating for armature impregnation, Electrostatic Technology Inc, Branford, CT, USA, 1977.

[15] F.S. Ali, T.E. Base, I.I. Inculet, IEEE Trans. Ind. Appl. 36 (1) (2000) 992.

[16] M. Barletta, G. Simone, V. Tagliaferri, J. Mater. Process. Technol. (2004 May) submitted for publication.

[17] A.G. Bailey, J. Electrost. 45 (1998) 85.

[18] Q. Ye, T. Steigleder, A. Scheibe, J. Domnick, J. Electrost. 54 (2002) 189.

[19] Q. Ye*, J. Domnick, Powder Technol. 135-136 (2003) 250. 